\title{
Ética da Propaganda Política
}

Emilia Paes ${ }^{1}$

Washington Olivetto, um dos publicitários mais famosos do Brasil, não faz propaganda política. "Isso fez com que eu me treinasse para trabalhar com a iniciativa privada, onde as decisões são profissionais e não políticas." ${ }^{2}$ E o que entendemos por decisão política? David Easton, cientista político canadense, diz que a ação é política quando está ligada à execução de decisões coercivas num dado sistema social. Ou seja, uma decisão política se utiliza de autoridade, de posição e não apenas do julgamento do profissional como publicitário ou como membro da sociedade. Jürgen Habermas vai mais além, salienta que o agir político, em última instância não pode fundamentar-se racionalmente. Em suma, uma ação política mexe diretamente com o nível de decisão da sociedade. Ao aliar o fazer político a profissionais treinados na retórica e na arte do encantamento, perde-se a imparcialidade que o eleitor deveria ter como aliada no processo de escolha do melhor candidato.

Segundo Afonso de Albuquerque e Marcia Ribeiro Dias em Propaganda Política e a Construção da Imagem Partidária no Brasil $^{3}$, os votos no Brasil se expressam sobretudo nominalmente. Sendo assim, os eleitores têm a tendência de escolher o candidato, analisando seu perfil separadamente do partido ao qual este participa. É fácil prever então o motivo dos trabalhos detalhados do time de publicitários em torno da persona do político. Ainda segundo os antropólogos os meios de comunicação de massa têm sido os formadores da opinião política da hipermodernidade que vivemos hoje. Não mais pós-modernidade, pois em nosso estado cultural, econômico e social, o consumo em massa substituiu antigos paradigmas de referência.

Ao tratarmos de meios de comunicação de massa, não só a publicidade vem a nossa mente como também o jornalismo. Cada vez mais se sabe que as linhas editoriais de cada emissora divergem quanto ao trato das notícias e apoios políticos. Vivemos na "sociedade do espetáculo" de Debord ${ }^{4}$, o real se diluiu e em seu lugar estereótipos e criações surgiram. Segundo Bauman em "Amor Líquido: sobre A Fragilidade Dos Laços Humanos" vivemos em um mundo de incerteza, extrema insegurança em relação à estabilidade de cada indivíduo dentro da sociedade e em relação à duração da ordem política, de relações sociais frágeis, mercantilizadas e individualizadas. Não há um referencial moral. Assim sendo, os políticos que observamos nos meios de comunicação nada são além de "produtos" moldados para serem "vendidos" para um público alvo determinado (que proporcione sua vitória) através

\footnotetext{
${ }^{1}$ Aluna do curso de Comunicação Social PUC-Rio, semestre 2015.2.

2 Cf:http://midiapublicitaria.com/blog/2015/05/28/politica-brasileira-como-e-feito-o-pao-e-circo/

${ }^{3}$ ALBUQUERQUE, Afonso de; DIAS, Marcia Ribeiro. Propaganda política e a construção da imagem partidária no Brasil. CIVITAS - Revista de Ciências Sociais, v.2, n.2, 2002.

4 DEBORD, Guy. A sociedade do espetáculo, disponível em

http://www.ebooksbrasil.org/adobeebook/socespetaculo.pdf acesso setembro 2015.

${ }^{5}$ BAUMAN, Zygmunt. Amor líquido: sobre a fragilidade dos laços humanos. Rio de Janeiro: Jorge Zahar Ed., 2004.
} 
da viralização, do espetáculo, das ações externas e outras técnicas passadas por "marqueteiros". Parece que tratar de política nunca envolveu imparcialidade ou verdade, que cada vez mais idolatramos seres vendáveis, descartáveis e que seu poder de administração pública não é discutido no ato da venda.

Ao pensar nos artifícios da "venda" e do espetáculo, lembro-me dos filmes nazistas criados durante o $3^{\circ}$ Reich. A atmosfera de enlevação espiritual do cidadão guerreiro, a beleza das paisagens, as pessoas asseadas, determinadas e até as decisões de filmagem provam que o filme foi forjado para fazer a população se acalmar e afirmar em suas mentes o quanto o nazismo era eficiente, a forma prática do progresso, e belo, quase divino. Tais filmes eram passados para todo o povo alemão e levavam a eles uma realidade que não se parecia nada com a real política interna e externa do governo de Hitler. Partindo para outros governos, me lembro de JK, Getúlio Vargas e Mussolini. Sendo os governos ditatoriais e/ou totalitários mais conhecidos por sua propaganda política vou explorar Juscelino Kubitschek, um dos primeiros presidentes do país a vender sua figura pessoal como foco logo ao se candidatar para presidente. Ele o fez em seus primeiros programas de rádio, demonstrando leveza e modernidade. Daí o futuro apelido de "presidente Bossa Nova". Segundo o livro "Na arena do marketing político."”, JK dizia em sua campanha aquilo que o povo de cada parte do país queria escutar. Sempre muito informado, viajou por todo o país com ótimos discursos e com apoio dos meios de comunicação mais fortes que na época pertenciam a Assis Chateaubriand, dono da maior rede de comunicação do país. Juscelino era presente e interagia com seus eleitores. Era e é considerado por muitos, populista. Creio que também podemos analisar que faz parte do todo governo populista as citadas características de JK. Chego à conclusão também que populismo não é populismo sem a participação de meios de comunicação de massa. Há algo de massificante no populismo até na imagem da palavra "populismo". Até na forma de contar a história de sua vida o ex-presidente acertou. As manchetes na época em que JK foi eleito diziam "O menino pobre de Diamantina é o novo presidente do Brasil." Superação vende. Hitler, um soldado raso ferido em guerra. Lula, um trabalhador sindicalista ferido em trabalho. Lincoln, um pobre menino branco que cortava lenha para viver. Um presidente que entendia tão bem de marketing pessoal foi coincidentemente fundamental para a abertura para o mercado externo e consequentemente mais propaganda e a vinda de mais agências para o país. Incrível. Elementar que apesar de Juscelino ter usado de propaganda ideológica, segundo o livro "Na arena do marketing político", nada se compara às propagandas de regimes políticos ditatoriais sendo essas muito mais autoritárias, nacionalistas e ilusórias.

O que questiono, como futura publicitária, é se o papel do publicitário é vender. Se esse o for não me sentiria confortável em participar do ato convencimento de uma venda política. Washington Olivetto entende que "A publicidade cria uma predisposição de compra, mas o

${ }^{6}$ QUEIROZ, Adolpho (Org.). Na arena do marketing político: ideologia e propaganda nas campanhas presidenciais brasileiras, São Paulo, Summus Editorial, 2006. 
julgamento final é do consumidor" ${ }^{\prime \prime}$. Me questiono que tipo de julgamento faz o consumidor que participa da sociedade-moda, da hipermodernidade, que mencionei anteriormente, em que as decisões de consumo e até a opinião pública se dão de acordo com a massa.

Questiono-me também sobre nossas criações publicitárias. Como o encantamento que somos orientados a saber criar é processado na mente do espectador? Me lembro de aprender na teoria que ao passarmos por um real experiência estética ${ }^{8}$, revelamos o desejo de permanecermos no estético mesmo quando saímos da presença do objeto encantador. Ou seja, vimos um filme de que gostamos muito, para nós aquela identificação com aquele produto foi sublime e isso se registrou em nossa mente. Se gostamos tanto, para termos mais contato com aquele filme que agora não podemos mais alcançar por completo (já assistimos), temos prazer em contar para amigos e familiares o quão boas são as cenas, a iluminação, as tomadas. Temos o prazer de lembrar as falas e assistir aquele pequeno "filminho mental" do que já vimos se repetir em nossa mente. Isso tráz de volta o prazer e o deleite que tivemos com aquele filme. Só assim o podemos ter novamente "perto" de nós. Partindo dessa ideia seria a proficiência de tentar proporcionar uma experiência estética no âmbito da propaganda política algo enganador? Imagine que o cidadão assiste a um filme político, se deleita com ele e apenas por isso o filme se inscreve em sua mente. Assim, ao falar bem de tal político não estaria ele levando uma imagem apenas espetaculosa para os demais? Até que ponto é ético um profissional de publicidade e propaganda contribuir então com a propaganda política?

A propaganda política se divide em quatro tipos: I) Propaganda Partidária II) Propaganda Interpartidária III) Propaganda Eleitoral IV) Propaganda Institucional. A propaganda eleitoral tem como meta captar o voto dos eleitores pela utilização de diversas formas de convencimento, como objetivos do futuro governo, que sugerem que o candidato apresentado é o mais indicado para ocupar um cargo público numa eleição concreta. Sua veiculação é permitida após o dia 5 de julho do ano eleitoral, ou seja, a partir de 6 de julho daquele ano (art. 36, caput, da Lei $9.504 / 97)$. No entanto, analisando as eleições de 2014, podemos ver que as formas de convencimento foram abandonadas e os partidos, ao exaltar os ânimos, recorreram a denúncias sensacionalistas, associações covardes e espetacularização do cenário político. O partido PSDB chegou a publicar um vídeo com uma animação da presidenta Dilma Rousseff, sendo perseguida por monstros. O vídeo intitulado "Os Monstros de Dilma" foi divulgado no facebook e teve como protagonistas do "terror" o "Jurássico PAC", a "Fantasmagórica Corrupção" e até um gigantesco "Godzilla Cubano", tentando dessa forma expor os problemas do governo ${ }^{9}$. As associações baixas do governo PT com o comunismo continuaram após o vídeo citar Cuba como um aliado do Partido dos Trabalhadores. Logicamente, aliados internacionais não significam que

\footnotetext{
${ }^{7} \mathrm{Cf:}$ http://veja.abril.com.br/blog/augusto-nunes/videos-veja-entrevista/washington-olivetto-publicitario/

${ }^{8} \mathrm{ROSA}$, Jorge Leandro. Experiência estética. Dicionário crítico de arte, imagem, linguagem e cultura. Disponível em: http://www.arte-

coa.pt/index. php? Language $=$ pt $\&$ Page $=$ Saberes $\&$ SubPage $=$ ComunicacaoELinguagemArte $\&$ Menu $2=A r t e V i d a E M e i o \&$ Slide $=118 \&$ Filtro $=118$.

${ }^{9} \mathrm{Cf}$ : http://www.cartacapital.com.br/blogs/carta-nas-eleicoes/psdb-usa-godzilla-cubano-contra-dilma-6708.html
} 
vamos adotar sua forma de governo, mas creio que isso não foi levado em conta pelo produtor do vídeo. Outro exemplo é o caso da propaganda pró governo Dilma que acusou o governo do candidato tucano de censurar jornalistas de Minas Gerais e fez acusações pessoais à família do candidato ${ }^{10}$. Foram tantas investidas entre os dois partidos que o TSE teve de intervir e proibir ataques aos adversários no tempo da propaganda eleitoral, que como vimos, tem como objetivo expor as propostas de governo. "O TSE reformula jurisprudência anterior, permissiva em matéria de propaganda eleitoral gratuita, caminhando no bom sentido de estabelecer que, nos programas eleitorais gratuitos, as propagandas têm de ser programáticas, propositivas. O debate pode ser ácido ou duro, mas relativo às questões programáticas e de políticas públicas"11, salientou o então presidente da Corte, ministro Dias Toffoli. Vale destacar que o "marqueteiro" do Aécio Neves nas eleições foi o publicitário Paulo Vasconcelos da Vitória Cl e de Dilma Rousseff foi João Santana, que já elegeu sete presidentes e tem a empresa Pólis Propaganda e Marketing.

Não é só no Brasil as confusões por propaganda política de gosto duvidoso. Na Rússia o partido de Vladimir Putin fez uso esse ano da seguinte propaganda: Uma menina nova vai a uma cartomante para falar de sua "primeira vez". Ela quer que seja por amor. Eis que a cartomante aponta nas cartas o candidato Putin e indica que ele é a escolha para que ela seja muito feliz. $O$ objetivo era alcançar pessoas que votam pela primeira vez, mas a campanha polêmica fez mais burburinho que agradou o eleitorado. Resultado: Mídia Espontânea. Ataques da oposição. Respostas desaforadas. Vitória de Putin ${ }^{12}$.

Em suma, após todos esses exemplos, podemos concluir que é ideal que a política exista em seu meio categórico que é o da coisa pública e do bem estar da sociedade. Porém, não entendo que deva o publicitário tratar da ordem política e ao fazer um bom trabalho de propaganda e marketing, dar a vitória ao seu cliente. Deve apenas o político apresentar um bom trabalho e uma boa proposta de governo para ser eleito. Um candidato que vai ajudar a gerir um país deve depender muito mais de seu ímpeto e sua vontade de fazer o país melhor do que de campanhas e mais campanhas bem estruturadas. Cito novamente Washington Olivetto que diz que, fora da esfera política, quando o produto é ruim e a propaganda boa, se descobre facilmente a farsa e não há reputação que resista ${ }^{13}$. O produto é descartado e não há nova compra. Assim sendo, não poderíamos adaptar essa lógica ao meio eleitoral? O eleito que não se mostrar eficiente ou faltar com os deveres públicos não poderia ser descoberto e perder assim qualquer intenção de voto futura? Melhor reformularmos essa "venda", afinal, o que você vende faz, para muitos, toda a diferença.

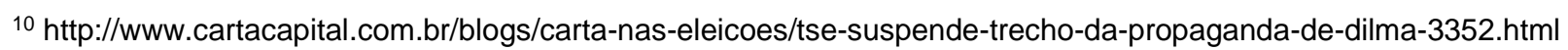

${ }^{11} \mathrm{Cf:}$ http://www.cartacapital.com.br/blogs/carta-nas-eleicoes/tse-suspende-trecho-da-propaganda-de-dilma3352.html.

12 Cf: http://noticias.r7.com/record-news/video/propaganda-politica-com-cartomante-gera-polemica-na-russia4f4fa89b92bb7f9e5ca7a84c/

${ }^{13} \mathrm{Cf:}$ http://veja.abril.com.br/blog/augusto-nunes/videos-veja-entrevista/washington-olivetto-publicitario/
} 


\section{Bibliografia}

ALBUQUERQUE, Afonso de; DIAS, Marcia Ribeiro. Propaganda política e a construção da imagem partidária no Brasil. CIVITAS - Revista de Ciências Sociais, v.2, n.2, 2002.

BAUMAN, Zygmunt. Amor líquido: sobre a fragilidade dos laços humanos. Rio de Janeiro: Jorge Zahar Ed., 2004.

DEBORD, Guy. A sociedade do espetáculo, disponível em http://www.ebooksbrasil.org/adobeebook/socespetaculo.pdf acesso em setembro 2015

ROSA, Jorge Leandro. Experiência estética. Dicionário crítico de arte, imagem, linguagem e cultura.

Disponível em:

http://www.artecoa.pt/index.php? Language $=$ pt\&Page $=$ Saberes $\&$ SubPage $=$ ComunicacaoELinguagemArte \&Me nu2=ArteVidaEMeio\&Slide=118\&Filtro=118. Acesso em setembro 2015.

QUEIROZ, Adolpho (Org.). Na arena do marketing político: ideologia e propaganda nas campanhas presidenciais brasileiras, São Paulo, Summus Editorial, 2006.

\section{Notícias}

http://www.cartacapital.com.br/blogs/carta-nas-eleicoes/psdb-usa-godzilla-cubano-contra-dilma6708.html http://oglobo.globo.com/brasil/julgamento-sobre-propaganda-com-elogio-de-dilma-aecio-causapolemica-toffoli-pede-vista-14313010 http://www.cartacapital.com.br/blogs/carta-nas-eleicoes/tse-suspende-trecho-da-propagandade-dilma-3352.html http://noticias.r7.com/record-news/video/propaganda-politica-com-cartomante-gera-polemicana-russia-4f4fa89b92bb7f9e5ca7a84c/ http://veja.abril.com.br/blog/augusto-nunes/videos-veja-entrevista/washington-olivettopublicitario/ 